\title{
Fluorescent gold nanoclusters for efficient cancer cell targeting
}

This article was published in the following Dove Press journal:

International Journal of Nanomedicine

\section{Rahul Purohit \\ Sanjay Singh}

Institute of Life Sciences, School of Science and Technology, Ahmedabad University, Ahmedabad, Gujarat, India
Correspondence: Sanjay Singh Institute of Life Sciences, School of Science and Technology, Ahmedabad University, Ahmedabad - 380009,

Gujarat, India

Tel +9l $79263024 \mid 4$

$\mathrm{Fax}+917926302419$

Email sanjay.singh@ahduni.edu.in

\begin{abstract}
Well-known surface properties of gold nanoparticles (AuNPs) offer easy surface modification with desired biomolecule, thus enabling them to be used for targeting and imaging of cancer cells/tissues. However, targeting and imaging capability come through after synthesis coating of AuNPs' surface with targeting or imaging molecules. Attempts have been made to conjugate both imaging and targeting molecules over the AuNPs, but have seen limited success. Hence, exploiting the fluorescence properties of gold nanoclusters (AuNCs), we have synthesized glucose-coated AuNCs for exhibiting both the imaging and targeting properties. These clusters have shown rapid and selective uptake in cancerous (A549) cells when compared with bovine serum albumin-coated AuNCs.
\end{abstract}

Keywords: gold nanoclusters, fluorescent AuNCs, cancer cell imaging and targeting

\section{Introduction}

Unique properties of bovine serum albumin (BSA)-coated gold nanoclusters (AuNCs) such as small size, high surface to volume ratio, in situ fluorescence, and biocompatibility (imparted due to the BSA coating) ${ }^{1}$ make them ideal candidates for studying the interaction of NCs with living systems (cells, tissues, organisms). The fluorescence properties exhibited by AuNCs can be used to track them easily within the biological system. AuNCs are nontoxic and stabile in the body fluids. Owing to their small size (2-3 nm), they interact with living system differently and do not elicit any immune response. It has been shown that almost all cancerous cells have a large number of glucose receptors that help in glucose uptake. ${ }^{2}$ The high glucose uptake is required for the high energy need of cancerous cells to meet their extra physiological requirements such as uncontrolled growth, cell division, metastasis, and angiogenesis. Exploiting this striking difference, we have synthesized novel glucose-coated AuNCs (Glu-AuNCs) to target the cancer cells, and BSA-AuNCs were synthesized as control.

\section{Experimental methods}

\section{AuNCs synthesis}

BSA-AuNCs were synthesized using BSA solution $(50 \mathrm{mg} / \mathrm{mL}, 5 \mathrm{~mL})$ and $\mathrm{HAuCl}_{4}$ (10 mM, $5 \mathrm{~mL}$ ) solution. Both solutions were mixed for 10 minutes followed by the addition of $\mathrm{NaOH}(1 \mathrm{M}, 0.5 \mathrm{~mL})$. Then, the solution was kept overnight with constant stirring. ${ }^{3}$ For the synthesis of Glu-AuNCs, glucose solution $(50 \mathrm{mg} / \mathrm{mL})$ was added to $\mathrm{HAuCl}_{4}$ solution $(10 \mathrm{mM} / \mathrm{mL})$, and total volume was made up to $5 \mathrm{~mL}$. The solution was stirred for 30 minutes followed by the addition of BSA solution. After mixing for 20 minutes, $\mathrm{NaOH}$ solution was added ( $1 \mathrm{M}, 0.75 \mathrm{~mL})$, and the solution was stirred overnight. Finally, AuNCs were dialyzed using $12.4 \mathrm{kDa}$ cutoff dialysis membranes 
to remove the free and unbounded glucose, $\mathrm{NaOH}$, and unreduced gold ions. Samples were stored at $4^{\circ} \mathrm{C}$ until use.

\section{Characterization}

AuNCs were characterized by ultraviolet-visible spectroscopy (Synergy HT, BioTek Instruments, Winooski, VT, USA), Fourier transform infrared spectroscopy (Shimadzu FTIR 8400S, Kyoto, Japan), and fluorescence spectroscopy (NanoLog Spectrofluorometer, Horiba Scientific, Kyoto, Japan).

\section{Uptake assay}

A549 cells were exposed to BSA-AuNCs and Glu-AuNCs for 6 hours for the uptake study and assessed by flow cytometer and fluorescent microscopy. A549 cells were commercially purchased from National Centre for Cell Sciences, Pune, India. For fluorescent microscopic imaging, cells $(\sim 5,000)$ were grown on coverslip for 24 hours. Subsequently, cells were washed and exposed to AuNCs for 6 hours followed by washing with phosphate-buffered saline and fixation with formaldehyde. Next, the cells were mounted on the glass slide and used for imaging.

\section{Results and discussion}

Ultraviolet-visible spectra recorded for BSA-AuNCs show absorption edge at $\sim 530 \mathrm{~nm},{ }^{4}$ whereas Glu-AuNCs showed absorption edge at $\sim 500 \mathrm{~nm}$ (Figure1A). This shift in absorbance maxima suggests that AuNCs are coated with glucose. The typical color of suspension of BSA-AuNCs and Glu-AuNCs is displayed in figure 1B. Both the suspensions look similar suggesting that the optical behavior of BSA-AuNCs does not change substantially after coating with glucose. This observation is in accordance with UV-vis spectra pattern of BSA-AuNCs and Glu-AuNCs (Figure 1A). It is well known that AuNCs $<3$ nm do not show well-defined surface plasmon resonance in the visible region, rather show absorption edge around $\sim 500 \mathrm{~nm}$.

BSA-AuNCs show maximum fluorescent emission intensity at $624 \mathrm{~nm}$, whereas Glu-AuNCs show a shift of $5 \mathrm{~nm}$ with the emission maxima being recorded at $629 \mathrm{~nm}$ (Figure 1D). BSA-AuNCs show a clean and narrow spectrum, whereas Glu-AuNCs show a slightly broader spectrum. For further confirmation of florescence nature of AuNCs after synthesis, we exposed AuNCs to ultraviolet light wavelength of $280 \mathrm{~nm}$. Clean bright fluorescence light was observed for both BSAAuNCs and Glu-AuNCs (Figure 1C). When BSA-AuNCs and Glu-BSA-AuNCs were exposed to the visible light, no fluorescence was observed (Figure 1A).

Human lung carcinoma cells (A549) are known to express many glucose receptors. Therefore, to check the selective uptake of Glu-AuNCs, we incubated the particles with A549 cells and compared the results with the uptake of BSA-AuNCs. To our surprise, the Glu-AuNCs uptake was more than BSA-AuNCs, which is clearly evident by intense green florescence from A549 cells when exposed to Glu-AuNCs (Figure 2). However BSA-AuNCs-treated cells showed meager fluorescence, which could be due to the endocytosis of particles. Therefore, the swift internalization of Glu-AuNCs in cancerous cells further confirms that these nanocomplexes could be used as a targeting molecule for cancerous cells. From our results, it can be concluded that Glu-AuNCs could be used for selective targeting (due to glucose) and imaging (due to AuNCs) of cancer cells.
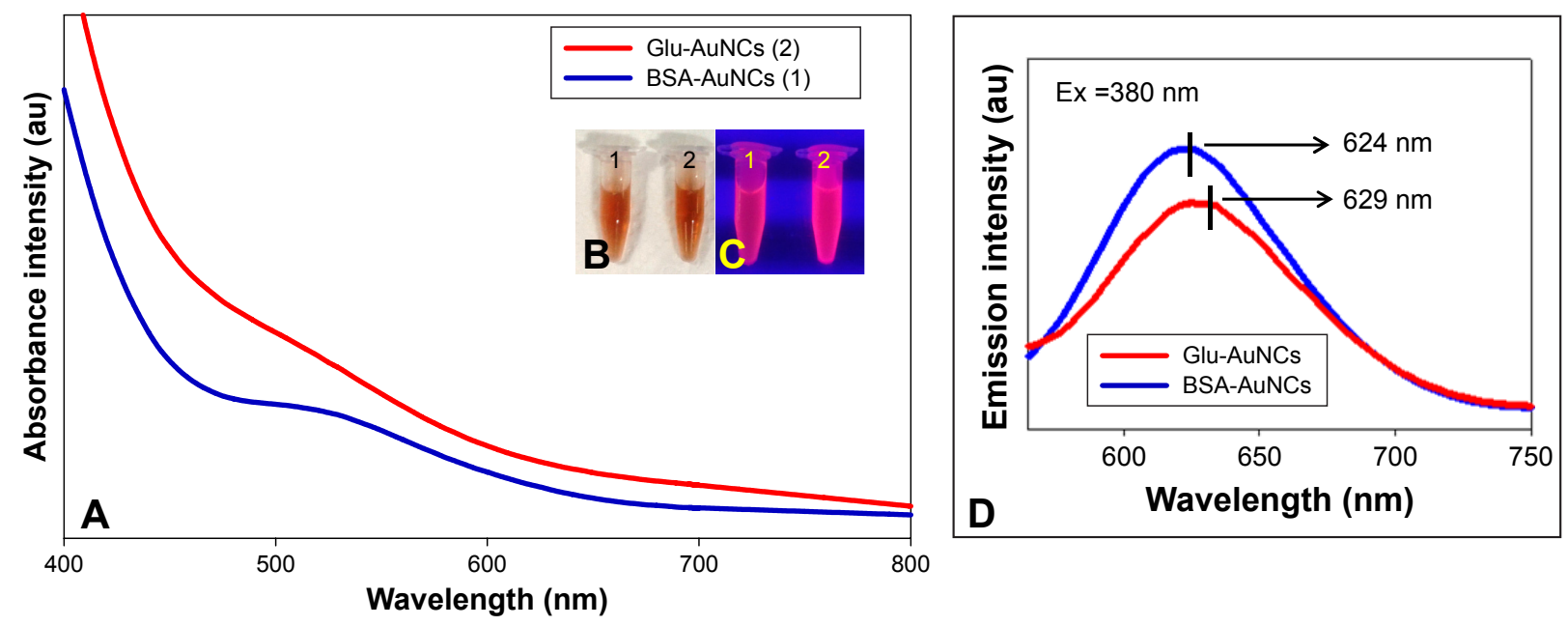

Figure I UV -Vis spectra (A) and fluorescent spectra (D) of BSA-based AuNCs and glucose-based AuNCs.

Notes: (B) AuNCs showing no fluorescence in absence of UV light. (C) AuNCs showing fluorescence in the presence of UV light.

Abbreviations: UV-Vis, ultraviolet visible; BSA, bovine serum albumin; AuNCs, gold nanoclusters; Glu, glucose; ex, excitation wavelength. 

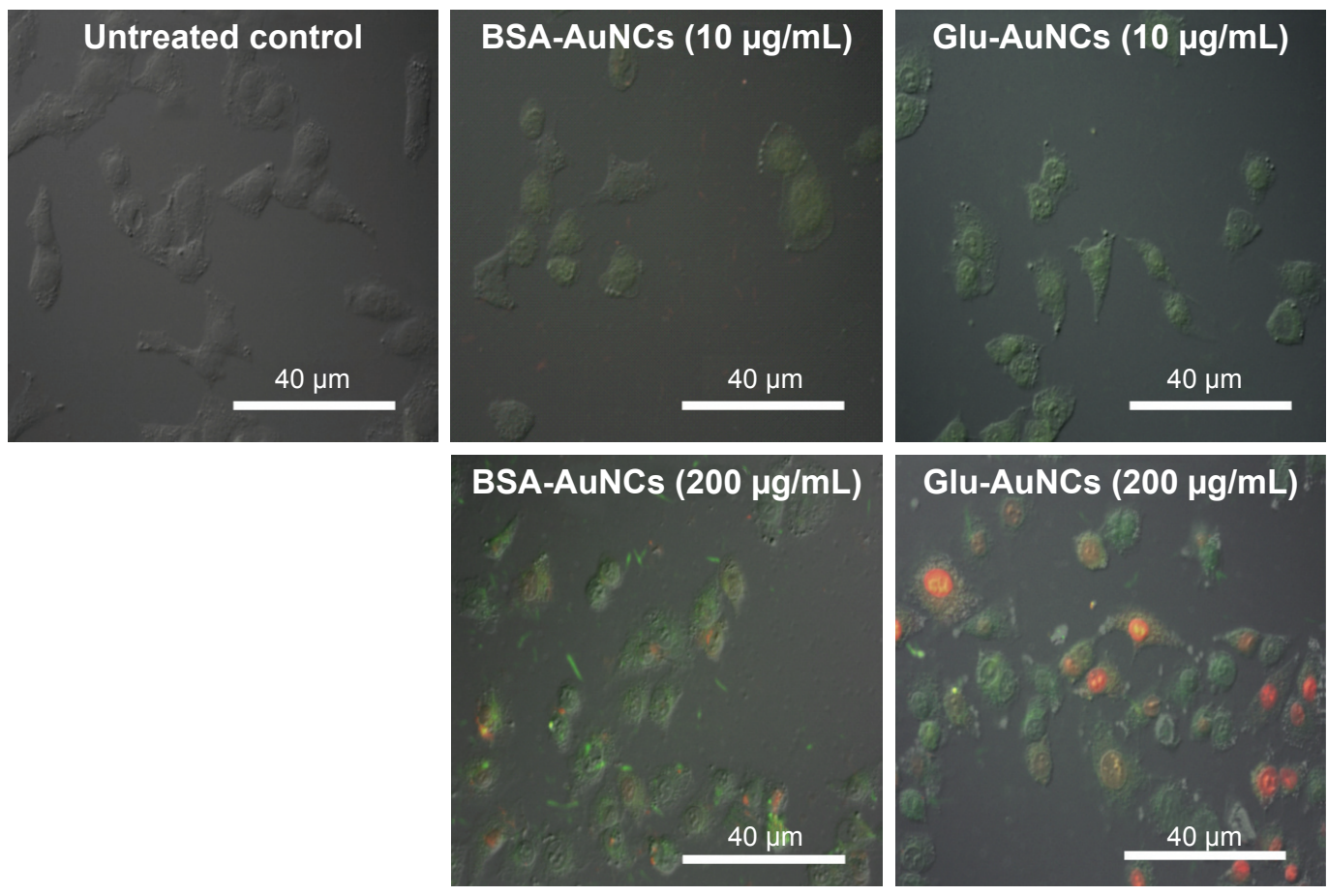

Figure 2 Uptake of BSA-AuNCs and Glu-AuNCs with different concentrations, using fluorescence microscope (400x magnification).

Abbreviations: BSA, bovine serum albumin; AuNCs, gold nanoclusters; Glu, glucose.

\section{Conclusion}

Our study shows the synthesis of stable and fluorescent BSAAuNCs and Glu-AuNCs. Glu-AuNCs show more uptake than BSA-AuNCs in cancerous cells at any given time. Therefore, these AuNCs can be used for selective targeting and imaging of cancerous cells.

\section{Acknowledgment}

The authors gratefully acknowledge the financial assistance from the Department of Chemistry, Indian Institute of Technology Madras, IITM (Grant no TTR1314010IITMTPRA), and the provision of laboratory and chemical facilities by the Centre for Nanotechnology Research and Applications (CENTRA) supported by The Gujarat Institute for Chemical Technology (GICT).

\section{Disclosure}

The authors report no conflicts of interest in this work.

\section{References}

1. Purohit R, Vallabani S, Shukla R, Kumar A, Dhawan A, Singh S. BSA coated gold nanoparticles exhibit size dependent interaction with lung cancer (A549) cells. Mol Cytogenet. 2014;7(1):83.

2. Jones RG, Thompson CB. Tumor suppressors and cell metabolism: a recipe for cancer growth. Genes Dev. 2009;23(5):537-548.

3. Liu JM, Jiang SL, Wang XX, et al. BSA-protected gold nanoclusters as fluorescent sensor for selective and sensitive detection of pyrophosphate. Anal Methods. 2013;5(16):3942-3947.

4. Li H, Guo Y, Xiao L, Chen B. Selective and sensitive detection of acetylcholinesterase activity using denatured protein-protected gold nanoclusters as a label-free probe. Analyst. 2014;139(1):285-290.
International Journal of Nanomedicine

\section{Publish your work in this journal}

The International Journal of Nanomedicine is an international, peerreviewed journal focusing on the application of nanotechnology in diagnostics, therapeutics, and drug delivery systems throughou the biomedical field. This journal is indexed on PubMed Central, MedLine, CAS, SciSearch ${ }^{\circledR}$, Current Contents ${ }^{\circledR} /$ Clinical Medicine,

\section{Dovepress}

Journal Citation Reports/Science Edition, EMBase, Scopus and the Elsevier Bibliographic databases. The manuscript management system is completely online and includes a very quick and fair peer-review system, which is all easy to use. Visit http://www.dovepress.com/ testimonials.php to read real quotes from published authors. 